\title{
The absolute lymphocyte/monocyte ratio recovery during ABVD treatment cycles is not significantly impacted by the use of myeloid growth factors and predicts clinical outcomes in classical Hodgkin lymphoma regardless of their use
}

This article was published in the following Dove Press journal:

Blood and Lymphatic Cancer: Targets and Therapy

23 July 2014

Number of times this article has been viewed

Gregory P Kaufman'

Kay M Ristow ${ }^{1,2}$

Svetomir N Markovic ${ }^{1,2}$

Luis F Porrata ${ }^{1,2}$

'Department of Internal Medicine, ${ }^{2}$ Division of Hematology, Mayo

Clinic, Rochester, MN, USA
Correspondence: Gregory P Kaufman Department of Internal Medicine, College of Medicine, Mayo Clinic, 200 First Street SW, Rochester, MN 55905, USA

Tel + I 50728425 II

Email kaufman.gregory@mayo.edu
Abstract: Risk stratification of patients with classical Hodgkin lymphoma (cHL) remains suboptimal. The ratio of the absolute lymphocyte count (ALC) to absolute monocyte count (AMC) both at diagnosis and during subsequent recovery from serial cycles of chemotherapy predicts survival in cHL, and possesses advantages over other commonly used prognostic markers. Myeloid growth factors (MGFs), while not strongly recommended for use in adriamycin, bleomycin, vinblastine, and dacarbazine (ABVD) treatment cycles, are not uncommonly used to prevent the negative consequences of neutropenia. The effect that MGFs have on the ALC/ AMC ratio during ABVD treatment cycles, if any, remains unclear. We retrospectively evaluated 208 patients with $\mathrm{cHL}$, who were diagnosed, treated, and followed at Mayo Clinic Rochester between 1990 and 2014, and who had quantifiable records for the use of MGFs during ABVD treatment cycles. Having an ALC/AMC ratio $<1.1$ during all treatment cycles was confirmed as being a negative predictor of overall and progression free survival (hazard ratio [HR] 0.06, 95\% confidence interval [CI] 0.03-0.14 and HR 0.08, 95\% CI 0.04-0.17, respectively). Data on both the ALC/AMC ratio and use of MGFs were available for 1,979 half treatment cycles. When stratified to whether or not MGFs were given, the change in the ALC/AMC ratio as compared to the prior half cycle was found to be statistically insignificant $(P=0.3445)$. No survival advantage was found with the administration of MGFs in any cycle of therapy (log rank $P=0.5713$ ). Our data validate the prognostic significance of having an ALC/AMC ratio of $\geq 1.1$ regardless of the use of MGFs.

Keywords: myeloid growth factors, classical Hodgkin lymphoma, survival ALC/AMC ratio, ABVD chemotherapy

\section{Introduction}

While the majority of patients with classical Hodgkin lymphoma (cHL) obtain favorable metrics of survival in comparison to other hematologic malignancies, the risk stratification of these patients remains suboptimal. ${ }^{1}$ Identification of patients at reduced risk of treatment failure remains particularly important in order to consider treatment reduction in chemotherapy cycles and adjuvant radiation dose. Reduction in therapy in such patients would not lead to worse cHL outcomes and could lead to long-term risk reduction for secondary malignancies and other complications of survivorship. ${ }^{2}$ 
In the age of cost-conscious medicine, markers of disease risk stratification that are relatively low-cost and easy to obtain are increasingly desirable. It has previously been shown that the peripheral blood absolute lymphocyte count (ALC) to absolute monocyte count (AMC) ratio $\left(\mathrm{R}^{\mathrm{ALC} / \mathrm{AMC}}\right)$ at diagnosis can predict outcomes in cHL.,4 Along with the observation that tumor associated macrophages influence clinical outcomes, the $\mathrm{R}^{\mathrm{ALC} / \mathrm{AMC}}$ highlights the importance of the relationship between the host immune system and innate tumor biology in the natural course of cHL. ${ }^{5}$ The limitation of the above markers, as well as the International Prognostic Score at diagnosis and stratification by interim positron emission tomography scan, lies in their inability to continuously assess host/tumor immune interaction during treatment cycles, as they are obtained at a single time point in the course of therapy. ${ }^{6,7}$ We have previously shown that the peripheral blood $\mathrm{R}^{\mathrm{ALC} / \mathrm{AMC}}$ during each cycle of therapy in cHL with adriamycin, bleomycin, vinblastine, and dacarbazine (ABVD) possesses prognosticative value in predicting clinical outcomes. ${ }^{8}$ The current study aims to validate the use of this easily obtained and inexpensive predictive marker with the concomitant utilization, or lack thereof, of myeloid growth factors (MGFs) (such as filgrastim and pegfilgrastim) during cycles of ABVD in cHL.

MGFs are used in cancer chemotherapy in an attempt to ameliorate the negative consequences of prolonged neutropenia and allow therapy to proceed without dose reduction or delay. Despite a primary increase in neutrophils following their administration, there is also evidence that MGFs affect the bone marrow's output of lymphocytes and monocytes in an uneven ratio, raising concerns that their use could impact the $\mathrm{R}^{\mathrm{ALC} / \mathrm{AMC}}{ }^{9}$ In cHL, ABVD is typically administered in two phases ("a" and "b") on day 1 and day 15 of each cycle, and is considered to have an intermediate risk (10\%-20\%) of causing febrile neutropenia. ${ }^{10}$ Current guidelines consider this intermediate risk an indication for clinicians to consider the use of MGFs, but do not give a strong endorsement for or against their use. ${ }^{11}$ There is conflicting data regarding both the necessity of MGFs to prevent complications of neutropenia in ABVD, as well as a potential role in increasing the risk of developing bleomycin related pulmonary toxicity. ${ }^{12-16}$ Despite these controversies, the use of MGFs in a real world clinical setting in the treatment of $\mathrm{cHL}$ is not uncommon. Validating the prognostic value of the $\mathrm{R}^{\mathrm{ALC} / \mathrm{AMC}}$ during count recovery of repetitive ABVD cycles in the treatment of cHL with or without the use of MGFs, remains an important unanswered question.

\section{Materials and methods Patients}

Two hundred and thirty-two patients with newly diagnosed cHL, treated with ABVD with or without radiation, and followed at Mayo Clinic (Rochester, MN, USA) between the years 1990 and 2014 were retrospectively identified. Patients were not included if they had a pathological diagnosis of nodular lymphocyte-predominant HL, were treated only with radiation or palliative care, had a concomitant autoimmune disease and were receiving immunosuppressive therapy, participated in clinical trials, or if they had HIV. All demographic and clinical information including age, sex, and hematologic labs were obtained from medical records. Institutional Review Board (IRB) approval was obtained in accordance with the Declaration of Helsinki. The $\mathrm{R}^{\mathrm{ALC} / \mathrm{AMC}}$ was obtained from the complete blood cell count (CBC) as previously described. ${ }^{8}$ Information regarding the use or lack of use of MGFs during each ABVD half-cycle, as well as the specific type and dose of growth factor given, was obtained from the computerized chemotherapy records (for ABVD cycles given after 2003) or from a prior paper record system (cycles given prior to 2003).

\section{End point}

The primary end point of the study was to assess if MGFs affect the $\mathrm{R}^{\mathrm{ALC} / \mathrm{AMC} C}$ recovery during ABVD chemotherapy. The secondary end point was to evaluate if MGFs have any impact on overall survival (OS) and progression-free survival (PFS) in cHL patients treated with ABVD chemotherapy.

The cut-off of an $\mathrm{R}^{\mathrm{ALC} / \mathrm{AMC}} \geq 1.1$ used in this study was based on our previous publications and obtained from the CBC count from a similar automated technology with devices that have included the Coulter STKR, Coulter STKS, Coulter GENS, Coulter LH500, Coulter LH750, Coulter HmX, Coulter AcT Diff5 (Beckman Coulter, Inc., Brea, CA, USA), Sysmex XE5000, Sysmex XE2100, Sysmex 1800, and Sysmex 200 (Sysmex Inc., Kobe, Japan), at each cycle phase of ABVD treatment., ${ }^{3,17}$ The $\mathrm{R}^{\mathrm{ALC} / \mathrm{AMC}}$ was obtained by dividing the absolute lymphocyte count (ALC) over the absolute monocyte count (AMC) from the $\mathrm{CBC}$ count at each cycle phase of ABVD chemotherapy.

\section{Prognostic factors}

The prognostic factors evaluated in the study included the International Prognostic Score (IPS) at diagnosis for advanced stage patients: age $>45$ years, albumin $<4 \mathrm{~g} / \mathrm{dL}$, ALC $<600$ cells $/ \mu \mathrm{L}$ or $<8 \%$ of white blood cell count, hemoglobin $<10.5 \mathrm{~g} / \mathrm{dL}$, male sex, stage IV and white blood cell count $\geq 15,000$ cells $/ \mu \mathrm{L}$; limited versus advanced stage; 
treatment modality (combination chemotherapy plus radiation versus chemotherapy alone), use of MGFs during treatment cycles, and the $\mathrm{R}^{\mathrm{ALC} / \mathrm{AMC}}$ during treatment cycles. ${ }^{18}$

\section{Statistical analysis}

Patient characteristics were described in percentages for nominal variables, while continuous variables were described with median and range. To determine whether the use of MGFs impacted subsequent $\mathrm{R}^{\mathrm{ALC} / \mathrm{AMC}}$ we calculated a $\Delta \mathrm{R}^{\mathrm{ALC} / \mathrm{AMC}}$ value, defined as the change in the ALC/AMC ratio from half ABVD cycle $n$ and half cycle $n-1$. The $\Delta R^{\text {ALC/AMC }}$ value was then stratified into whether or not the patient received a MGF between the date of the CBC count determining the $\mathrm{R}^{\mathrm{ALC} / \mathrm{AMC}}$ for cycle $\mathrm{n}-1$ and cycle $\mathrm{n}$ which was typically obtained when the patient came in for the following half cycle. Specifically, for cycle 1 a the $\triangle \mathrm{R}^{\mathrm{ALC} / \mathrm{AMC}}$ was calculated

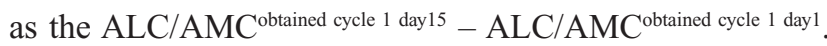
For the last half cycle the $\mathrm{R}^{\mathrm{ALC} / \mathrm{AMC}}$ was taken from a subsequent $\mathrm{CBC}$ between 2 and 4 weeks following the last dose of chemotherapy. If no such lab value was available, the last half cycle was not included in the analysis as no $\Delta \mathrm{R}^{\mathrm{ALC} / \mathrm{AMC}}$ could be accurately calculated. The Wilcoxon rank sum test


all cycles depending on whether or not MGFs were given for the particular half cycle in which each individual $\Delta \mathrm{R}^{\mathrm{ALC} / \mathrm{AMC}}$ was calculated. For each individual half cycle of ABVD a Wilcoxon rank sum test was performed to compare the mean $\Delta \mathrm{R}^{\mathrm{ALC} / \mathrm{AMC}}$ for that cycle depending on whether or not MGFs were given. Also, for each individual half cycle of ABVD the Wilcoxon rank sum test was performed on groups of patients with a $\mathrm{R}^{\mathrm{ALC} / \mathrm{AMC}} \geq 1.1$ as well as $<1.1$ for cohorts of patients who did and did not receive MGFs for that half cycle. Survival curves were constructed using Kaplan-Meier estimates and the log-rank test was used to detect differences. Cox proportional hazard analysis was performed for both univariate and multivariate factors, including the use and number of cycles MGFs were given, to assess their predictability on PFS and OS. JMP version10 (SAS Institute Inc, Cary, NC, USA) was used for statistical analysis.

\section{Results}

Two hundred and eight of the 232 eligible patients were evaluable for inclusion in final analysis. Twenty-four patients were excluded for lack of data on the use of MGFs. In total, 1,979 half treatment cycles were evaluable and had data on the use of MGFs as well as a $\mathrm{R}^{\mathrm{ALC} / \mathrm{AMC}}$ for that cycle phase and the cycle preceding it. Median age at diagnosis was 36 years, and $54 \%$ of patients were male. Median follow up for the entire cohort from diagnosis was 64.5 months (1-270), and was 72 months (10-270) for the 179 patients alive at last follow-up. Overall, 69\% of patients received MGFs in any cycle and the median number of half cycles was $3(0-12)$. Of the patients who received any MGF, the median number of half cycles in which growth factors were given was 6 (1-12). Twenty-eight percent of patients had greater than or equal to three IPS risk factors at diagnosis, and 54\% were treated with chemotherapy alone. The baseline characteristics are detailed in Table 1.

To test whether there was a difference in the $\mathrm{R}^{\mathrm{ALC} / \mathrm{AMC}}$ depending on the use of MGFs, the Wilcoxon rank sum test was performed for each 12 half cycles of ABVD. These results are summarized in Table 2 . In all 12 half cycles, there was no statistically significant difference in the $\Delta \mathrm{R}^{\mathrm{ALC} / \mathrm{AMC}}$ When all half cycles were split on the basis of the use of MGFs, an average $\Delta \mathrm{R}^{\mathrm{ALC} / \mathrm{AMC}}$ was calculated for each patient, the Wilcoxon signed rank test showed a $P$-value of 0.3445 indicating no statistical difference between the two groups.

To confirm our previous reported finding that patients with a $\mathrm{R}^{\mathrm{ALC} / \mathrm{AMC}}$ less than 1.1 in all cycles of therapy have a worse prognosis, survival curves were constructed and shown in Figure 1A. There was no difference in OS between patients who received MGFs and those who did not receive them in any cycle ( $\log$ rank $P=0.5713)$. However, patients who received MGFs in $>3$ half cycles had statistically superior OS as compared to patients who received MGFs in $<3$ half cycles ( $\log$ rank $P=0.0288$ ) Figure $1 \mathrm{~B}$ and C. Similar findings were found looking at PFS and are shown in Figure 1D-F respectively.

Cox-proportional hazard analysis focusing on the potential effects of MGFs on OS and PFS showed that the use of MGFs in the majority of individual treatment cycles, as well as the use, or lack of use of MGFs, in any treatment cycle did not impact OS or PFS (Table 3). Multivariate analysis showed that while having a $\mathrm{R}^{\mathrm{ALC} / \mathrm{AMC}} \geq 1.1$ in any cycle as well as having an IPS score $<3$ at diagnosis strongly predicted survival, the use of MGF in any cycle did not have a statistical impact on OS or PFS (HR [95\% CI] 0.80 [0.37-1.79] and 0.74 [0.40-1.40] for OS and PFS, respectively).

\section{Discussion}

The $\mathrm{R}^{\mathrm{ALC} / \mathrm{AMC}}$ recovery during $\mathrm{ABVD}$ treatment cycles for cHL predicts clinical outcomes. Our current data validate this prognostic biomarker in the setting of MGF use. As there has been preclinical data which has shown a differential increase in lymphocytes and monocytes following MGF administration, it was reasonable to query whether their use has an 
Table I Baseline patient characteristics $(n=208)$

\begin{tabular}{|c|c|c|}
\hline Variable & Percentage & Median (range) \\
\hline Age at diagnosis & - & $36(18-89)$ \\
\hline Male sex & 54 & - \\
\hline Clinical follow-up (months) & - & $64.5(I-270)$ \\
\hline \multicolumn{3}{|l|}{ Stage } \\
\hline 1 & 5.3 & - \\
\hline II & 45.2 & - \\
\hline III & 28.4 & - \\
\hline IV & 21.2 & - \\
\hline \multicolumn{3}{|l|}{ Initial treatment } \\
\hline $\mathrm{CT}+\mathrm{RT}$ & 45.7 & - \\
\hline CT & 54.3 & - \\
\hline \multicolumn{3}{|l|}{ IPS } \\
\hline Age (years) $\geq 45$ & 36.0 & - \\
\hline Albumin $(\mathrm{g} / \mathrm{dL}) \mathrm{n}=176<4$ & 47.2 & - \\
\hline $\mathrm{Hgb}(\mathrm{g} / \mathrm{dL})<10.5$ & 14.9 & - \\
\hline $\mathrm{WBC} \times 10^{9} / \mathrm{L} \geq 15$ & 12.5 & - \\
\hline Male & 54 & - \\
\hline Stage IV & 21.2 & - \\
\hline IPS factors index $\geq 3$ & 28.4 & - \\
\hline \multicolumn{3}{|l|}{ Number of cycles given } \\
\hline 2 & 8.7 & - \\
\hline 3 & 2.9 & - \\
\hline 4 & 28.8 & - \\
\hline 5 & 2.4 & - \\
\hline 6 & 56.7 & - \\
\hline Received any MGFs & 69.7 & - \\
\hline Number of half cycles MGFs given & - & $3(0-12)$ \\
\hline \multicolumn{3}{|l|}{ Cycle IA ( $(n=208)$} \\
\hline ALC/AMC ratio & - & $2.1(0.15-85.5)$ \\
\hline MGF used & 9.0 & - \\
\hline \multicolumn{3}{|l|}{ Cycle IB (n=206) } \\
\hline ALC/AMC ratio & - & $2.26(0.22-37.5)$ \\
\hline MGF used & 44.7 & - \\
\hline \multicolumn{3}{|l|}{ Cycle 2A (n=204) } \\
\hline ALC/AMC ratio & - & $1.98(0.22-60.2)$ \\
\hline MGF used & 40.7 & - \\
\hline \multicolumn{3}{|l|}{ Cycle 2B (n=204) } \\
\hline ALC/AMC ratio & - & $1.90(0.17-26.5)$ \\
\hline MGF used & 44.6 & - \\
\hline \multicolumn{3}{|l|}{ Cycle 3A (n=188) } \\
\hline ALC/AMC ratio & - & $1.88(0.15-20.8)$ \\
\hline MGF used & 42.6 & - \\
\hline \multicolumn{3}{|l|}{ Cycle 3B (n=188) } \\
\hline ALC/AMC ratio & - & $1.67(0.15-9.83)$ \\
\hline MGF used & 47.8 & - \\
\hline \multicolumn{3}{|l|}{ Cycle 4A $(n=183)$} \\
\hline ALC/AMC ratio & - & $1.67(0.20-19.4)$ \\
\hline MGF used & 43.1 & - \\
\hline \multicolumn{3}{|l|}{ Cycle 4B $(n=|8|)$} \\
\hline ALC/AMC ratio & - & $1.80(0.26-5.79)$ \\
\hline MGF used & 40.2 & - \\
\hline \multicolumn{3}{|l|}{ Cycle 5A (n=122) } \\
\hline ALC/AMC ratio & - & $1.78(0.32-9.25)$ \\
\hline MGF used & 52.5 & - \\
\hline \multicolumn{3}{|l|}{ Cycle 5B (n=|2I) } \\
\hline ALC/AMC ratio & - & $1.70(0.33-14.22)$ \\
\hline MGF used & 50.4 & - \\
\hline
\end{tabular}

Table I (Continued)

\begin{tabular}{lll}
\hline Variable & Percentage & Median (range) \\
\hline Cycle 6A $(\mathrm{n}=\mathrm{II})$ & & \\
ALC/AMC ratio & - & $\mathrm{I} .63(0.30-30.00)$ \\
MGF used & 48.3 & - \\
Cycle 6B $(\mathrm{n}=\mathrm{I} \mid 6)$ & & \\
ALC/AMC ratio & - & $1.63(0.39-10.00)$ \\
MGF used & $4 \mathrm{I} .4$ & - \\
\hline
\end{tabular}

Abbreviations: Hgb, hemoglobin; CT, chemotherapy; RT, radiation therapy; IPS, International Prognostic Score; MGF, myeloid growth factor; ALC, absolute lymphocyte count; AMC, absolute monocyte count; WBC, white blood cell count.

identifiable impact on the following half cycle's CBC count and $\mathrm{R}^{\mathrm{ALC} / \mathrm{AMC}}$, as this could have a confounding effect on the cutoff previously reported. ${ }^{9}$ However, our data show that in the majority of cycles there is no statistical difference in the $\mathrm{R}^{\mathrm{ALC} / \mathrm{AMC}}$ as compared to the most recent cycle whether MGFs were used or not. As there are other unmeasurable factors that can influence bone marrow production of non-neutrophilic leukocytes, such as exposure to certain pathogens, we used the Wilcoxon rank sum test to compare groups as the data did not satisfy an assumed normal distribution. The limitation of our study is in its retrospective design and the long period of time (14 years) over which data were collected. Future prospective confirmatory studies should be undertaken to confirm our findings.

Our data show a small statistically significant OS and PFS benefit when patients are dichotomized by whether they received $>3$ half cycles of ABVD inclusive of MGFs.

Table 2 Comparison of the $\triangle \mathrm{R}^{\mathrm{ALC} / A M C}$ dependent on MGF status for 12 ABVD half cycles

\begin{tabular}{llll}
\hline Cycle (n) & $\begin{array}{l}\text { Wilcoxon rank sum } \\
\Delta \mathbf{R}^{\text {ALCIAMC }} \text { (MGF vs } \\
\text { no MGF in 1/2 cycle) }\end{array}$ & $\begin{array}{l}\text { Subgroup } \\
\boldsymbol{P} \text {-value }\end{array}$ & $\begin{array}{l}\text { Subgroup } \\
\boldsymbol{P} \text {-value }\end{array}$ \\
& $\boldsymbol{P}$-value & & \\
\hline IA (208) & 0.192 I & $\mathrm{R}^{\text {ALCIAMC } \geq I . I}$ & $\mathrm{R}^{\text {ALCIAMC }}<$ I.I \\
& & 0.2657 & 0.4922 \\
IB (206) & 0.3452 & 0.1658 & 0.1106 \\
2A (204) & 0.4512 & 0.1221 & $0.0315^{*}$ \\
2B (204) & 0.3864 & 0.4973 & 0.4524 \\
3A (I88) & 0.2612 & 0.8267 & 0.1746 \\
3B (I88) & 0.6263 & 0.6355 & 0.8135 \\
4A (I83) & 0.2676 & 0.3234 & 0.2652 \\
4B (I8I) & 0.1054 & 0.2738 & 0.0852 \\
5A (I22) & 0.6127 & 0.8618 & 0.7985 \\
5B (I2I) & 0.0851 & 0.1164 & 0.5338 \\
6A (II8) & 0.1523 & 0.3009 & 0.4277 \\
6B (II6) & 0.6419 & 1.0000 & 0.4440 \\
\hline
\end{tabular}

Note: * indicates statistical significance of $P$-value $<0.05$ of Wilcoxon rank sum test comparing groups indicated in columns.

Abbreviations: ALC, absolute lymphocyte count; AMC, absolute monocyte count; ABVD, adriamycin, bleomycin, vinblastine, and dacarbazine; MGF, myeloid growth factor; vs, versus. 

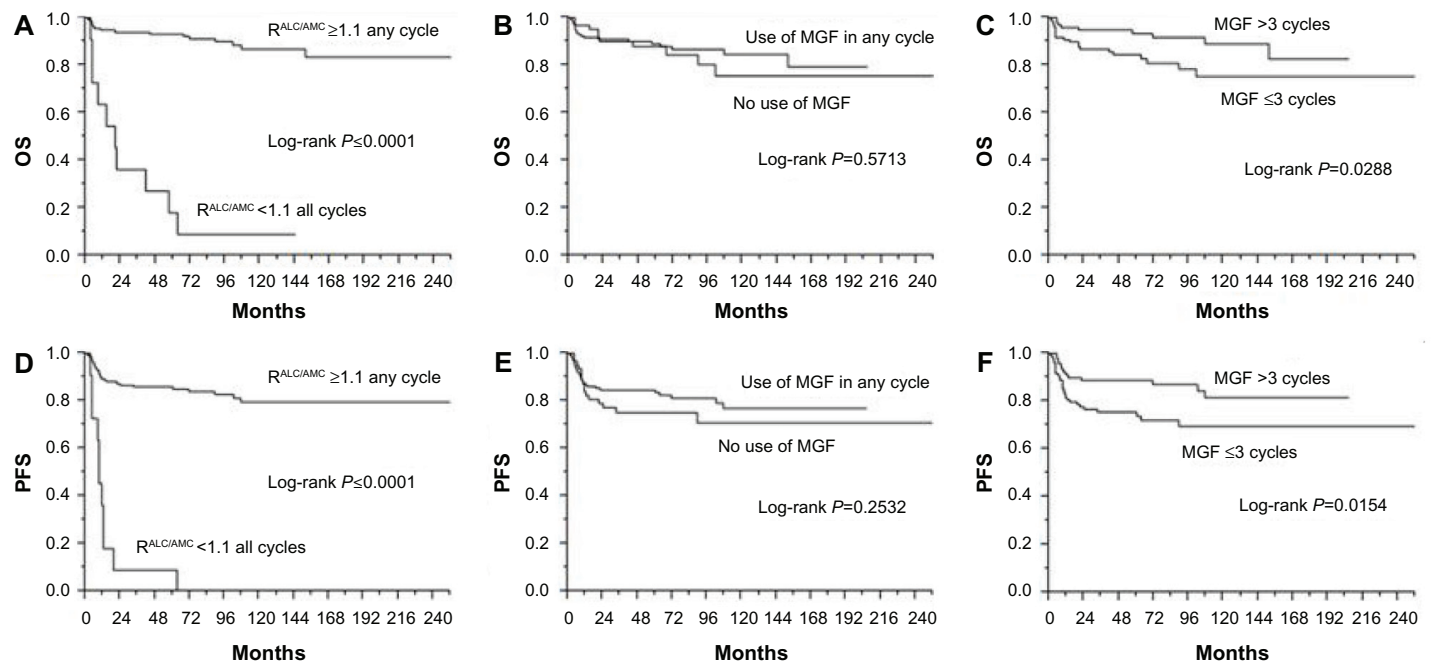

Figure I Overall (A-C) and progression free survival (D-F) dependent on RALCAMC and MGF use status.

Abbreviations: ALC, absolute lymphocyte count; AMC, absolute monocyte count; MGF, myeloid growth factor; OS, overall survival; PFS, progression free survival.

The clinical significance of this observation is minimal, and it should be noted that patients who received no MGFs had equivalent clinical outcomes to those who received any MGFs. The lack of impact of MGFs on OS is consistent with other reported literature, and clinical guidelines on their use. ${ }^{19}$
The observation of the $\mathrm{R}^{\mathrm{ALC} / \mathrm{AMC}}$ as a predictor of OS has been shown to hold true in other disease settings in addition to $\mathrm{cHL} .{ }^{20}$ The specter of being able to manipulate the $\mathrm{R}^{\mathrm{ALC} / \mathrm{AMC}}$ for therapeutic advantage is appealing, if done in a way that meaningfully adjuncts the relationship of the host immune system to the tumor micro-environment. Our data show that

Table 3 Univariate and multivariate analysis for overall and progression free survival

\begin{tabular}{|c|c|c|c|c|}
\hline \multirow[t]{2}{*}{ Variable } & \multicolumn{2}{|l|}{ OS } & \multicolumn{2}{|l|}{ PFS } \\
\hline & HR (95\% Cl) & $P$-value & HR (95\% Cl) & $P$-value \\
\hline \multicolumn{5}{|l|}{ Univariable analysis } \\
\hline Cycle IA use of MGFs & $2.11(0.7 I-5.10)$ & 0.16 & $2.02(0.82-4.26)$ & 0.12 \\
\hline Cycle IB use of MGFs & $1.17(0.56-2.45)$ & 0.67 & $0.88(0.47-1.6 I)$ & 0.68 \\
\hline Cycle 2A use of MGFs & $0.97(0.45-2.06)$ & 0.95 & $0.93(0.49-1.72)$ & 0.82 \\
\hline Cycle 2B use of MGFs & $0.32(0.12-0.74)$ & $0.007^{*}$ & $0.30(0.14-0.61)$ & $0.001 *$ \\
\hline Cycle $3 \mathrm{~A}$ use of MGFs & $0.45(0.18-1.04)$ & 0.06 & $0.46(0.22-0.90)$ & $0.022 *$ \\
\hline Cycle 3B use of MGFs & $0.37(0.14-0.86)$ & $0.020 *$ & $0.43(0.2 \mathrm{I}-0.83)$ & $0.012^{*}$ \\
\hline Cycle 4A use of MGFs & $0.72(0.90-1.62)$ & 0.43 & $0.56(0.27-1.08)$ & 0.09 \\
\hline Cycle 4B use of MGFs & $0.46(0.17-1.14)$ & 0.09 & $0.59(0.28-1.18)$ & 0.14 \\
\hline Cycle 5A use of MGFs & $0.86(0.29-2.52)$ & 0.78 & $0.59(0.27-1.26)$ & 0.17 \\
\hline Cycle 5B use of MGFs & $0.55(0.17-1.66)$ & 0.29 & $0.48(0.20-1.05)$ & 0.07 \\
\hline Cycle 6A use of MGFs & $0.47(0.13-1.50)$ & 0.21 & $0.46(0.19-1.04)$ & 0.06 \\
\hline Cycle 6B use of MGFs & $0.64(0.17-2.05)$ & 0.47 & $0.50(0.20-1.16)$ & 0.11 \\
\hline Use of MGFs in any cycle & $0.80(0.38-1.80)$ & 0.58 & $0.70(0.38-1.33)$ & 0.27 \\
\hline Number of cycles (0-12) MGFs used & $0.31(0.08-1.01)$ & 0.05 & $0.36(0.12-0.95)$ & $0.039 *$ \\
\hline Any cycle $R^{\text {ALC/AMC }} \geq 1.1$ & $0.06(0.03-0.14)$ & $<0.000 I^{*}$ & $0.08(0.04-0.17)$ & $<0.0001 *$ \\
\hline IPS $\geq 3$ at diagnosis & $4.25(2.04-9.13)$ & $0.000 I^{*}$ & $2.86(1.56-5.22)$ & $0.0008^{*}$ \\
\hline \multicolumn{5}{|l|}{ Multivariable analysis } \\
\hline Use of MGF in any cycle & $0.80(0.38-1.82)$ & 0.5829 & $0.74(0.40-1.42)$ & 0.36 \\
\hline Any cycle $R^{\text {ALCIAMC }} \geq 1.1$ & $0.10(0.04-0.24)$ & $<0.000 I^{*}$ & $0.11(0.05-0.25)$ & $<0.000$ I* \\
\hline IPS $\geq 3$ at diagnosis & $2.59(1.13-5.97)$ & $0.0245^{*}$ & $2.00(1.03-3.84)$ & $0.04 I^{*}$ \\
\hline
\end{tabular}

Note: * indicates $P<0.05$.

Abbreviations: OS, overall survival; PFS, progression free survival; HR, hazard ratio; $\mathrm{Cl}$, confidence interval; MGF, myeloid growth factor; ALC, absolute lymphocyte count; AMC, absolute monocyte count; IPS, International Prognostic Score. 
the use of MGFs during ABVD does not consistently have an altering effect on the $\mathrm{R}^{\mathrm{ALC} / \mathrm{AMC}}$, and does not have a clinically significant influence on OS and PFS. The $\mathrm{R}^{\mathrm{ALC} / \mathrm{AMC}}$ is not meaningfully affected by the use of MGFs during cycles of ABVD in cHL.

\section{Disclosure}

The authors declare no conflicts of interest in this work.

\section{References}

1. Diehl V, Stein H, Hummel M, Zollinger R, Connors JM. Hodgkin's lymphoma: biology and treatment strategies for primary, refractory, and relapsed disease. Hematology Am Soc Hematol Educ Program. 2003: 225-247.

2. Thompson CA, Mauck K, Havyer R, Bhagra A, Kalsi H, Hayes SN. Care of the Adult Hodgkin Lymphoma Survivor. Am J Med. 2011; 124(12):1106-1112.

3. Porrata LF, Ristow K, Colgan JP, et al. Peripheral blood lymphocyte/ monocyte ratio at diagnosis and survival in classical Hodgkin's lymphoma. Haematologica. 2012;97(2):262-269.

4. Koh YW, Kang HJ, Park C, et al. The Ratio of the Absolute Lymphocyte Count to the Absolute Monocyte Count Is Associated with Prognosis in Hodgkin's Lymphoma: Correlation with Tumor-Associated Macrophages. Oncologist. 2012;17(6):871-880.

5. Steidl C, Lee T, Shah SP, et al. Tumor-Associated macrophages and Survival in Classical Hodgkin's Lymphoma. $N$ Engl $J$ Med. 2010;362(10):875-885.

6. Moccia AA, Donaldson J, Chhanabhai M, et al. International Prognostic Score in Advanced-Stage Hodgkin's Lymphoma: Altered Utility in the Modern Era. J Clin Oncol. 2012;30(27):3383-3388.

7. Hutchings M, Loft A, Hansen M, et al. FDG-PET after two cycles of chemotherapy predicts treatment failure and progression-free survival in Hodgkin lymphoma. Blood. 2006;107(1):52-59.

8. Porrata LF, Ristow KM, Habermann TM, et al. Peripheral blood absolute lymphocyte/monocyte ratio recovery during ABVD treatment cycles predicts clinical outcomes in classical Hodgkin lymphoma. Blood Cancer J. 2013;3:e110

9. Böhme M, Schmidt D, Radke J, Morenz J, Weise W. Effect of granulocyte colony stimulating factor (G-CSF) on peripheral blood leukocytes and lymphocytes in patients with chemotherapy-induced leukopenia. Geburtshilfe Frauenheilkd. 1994;54(12):670-674. German.
10. Lyman GH, Kuderer NM, Crawford J, et al. Predicting Individual Risk of Neutropenic Complications in Patients Receiving Cancer Chemotherapy. Cancer. 2011;117(9):1917-1927.

11. National Comprehensive Cancer Network. Myeloid Growth Factors (Version 1.2014). http://www.nccn.org/professionals/physician_gls/ pdf/myeloid_growth.pdf. Accessed March 14, 2014.

12. Younes A, Fayad L, Romaquera J, Pro B, Goy A, Wang M. Safety and efficacy of once-per-cycle pegfilgrastim in support of ABVD chemotherapy in patients with Hodgkin lymphoma. Eur J Cancer. 2006;42(17):2976-2981.

13. Evens AM, Cilley J, Ortiz T, et al. G-CSF in not necessary to maintain over $99 \%$ dose-intensity with ABVD in the treatment of Hodgkin lymphoma: low toxicity and excellent outcomes in a 10-year analysis. Br J Haematol. 2007;137(6):545-552.

14. Boleti E, Mead GM. ABVD for Hodgkin's lymphoma: full-dose chemotherapy without dose reductions or growth factors. Ann Oncol. 2007;18(2):376-380.

15. Saxman SB, Nichols CR, Einhorn LH. Pulmonary Toxicity in Patients with Advanced-Stage Germ Cell Tumors Receiving Bleomycin with and Without Granulocyte Colony Stimulating Factor. Chest. 1997;111(3):657-660.

16. Martin WG, Ristow KM, Habermann TM, Colgan JP, Witzig TE, Ansell SM. Bleomycin Pulmonary Toxicity Has a Negative Impact on the Outcome of Patients With Hodgkin's Lymphoma. J Clin Oncol. 2005;23(30):7614-7620.

17. Cox CJ, Habermann TM, Payne BA, Klee GG, Pierre RV. Evaluation of the Coulter counter model S-Plus IV. Am J Clin Pathol. 1985;84(3): 297-306.

18. Hasenclever D, Diehl V. A prognostic score for advanced Hodgkin disease. International Prognostic Factors Project on Advanced Hodgkin's Disease. N Engl J Med. 1998;339(21):1506-1514.

19. Ösby E, Hagberg H, Kvaløy S, et al. CHOP is superior to CNOP in elderly patients with aggressive lymphoma while outcome is unaffected by filgrastim treatment: results of a Nordic Lymphoma Group randomized trial. Blood. 2003;101(10):3840-3848.

20. Porrata LF, Ristow K, Habermann TM, et al. Absolute monocyte/lymphocyte count prognostic score is independent of immunohistochemically determined cell of origin in predicting survival in diffuse large B-cell lymphoma. Leuk Lymphoma. 2012;53(11): 2159-2165.
Blood and Lymphatic Cancer: Targets and Therapy

\section{Publish your work in this journal}

Blood and Lymphatic Cancer: Targets and Therapy is an international, peer-reviewed, open access journal focusing on blood and lymphatic cancer research, identification of therapeutic targets and the optimal use of preventative and integrated treatment interventions to achieve improved outcomes, enhanced survival and quality of life for the

\section{Dovepress}

cancer patient. The manuscript management system is completely online and includes a very quick and fair peer-review system. Visit http://www.dovepress.com/testimonials.php to read real quotes from published authors. 